\title{
UV-Vis Spectrophotometry Coupled to Chemometric Analysis for the Evaluation of Atrazine Photolysis and Photocatalysis
}

\section{Ailton Jose Moreira ( $\sim$ aijomoquim@gmail.com )}

Universidade Federal de São Carlos https://orcid.org/0000-0003-0741-8840

\section{Sherlan Lemos}

Universidade Federal da Paraiba

Dyovani Coelho

UFSCar CCET: Universidade Federal de Sao Carlos Centro de Ciencias Exatas e de Tecnologia

Lucia Mascaro

UFSCar CCET: Universidade Federal de Sao Carlos Centro de Ciencias Exatas e de Tecnologia

Gian Freschi

UNIFAL-MG: Universidade Federal de Alfenas

\section{Ernesto Pereira}

UFSCar CCET: Universidade Federal de Sao Carlos Centro de Ciencias Exatas e de Tecnologia

\section{Research Article}

Keywords: Photodegradation. Chemometrics. Atrazine. Hydroxyatrazine. Degradation mechanism.

Posted Date: September 9th, 2021

DOI: https://doi.org/10.21203/rs.3.rs-806984/v1

License: (1) This work is licensed under a Creative Commons Attribution 4.0 International License.

Read Full License 


\section{Abstract}

In this study, a spectrophotometric-chemometric (Spec-Chem) approach was applied as an alternative to chromatography to monitor ATZ and by-products after photolytic and photocatalytic oxidation aiming to unveil the ATZ degradation mechanism. Spec-Chem is an accessible, easy-to-operate, low-cost analytical approach to monitor atrazine (ATZ) and by-products and its applicability was validated by HPLC, the reference technique for the evaluation of pollutants degradation mechanisms. The chromatographic (DChro) and spectrophotometric (DSpec) data found 95\% and 57\% ATZ removal after $30 \mathrm{~min}$, respectively, proving that the DSpec erroneously induces a 38\% loss in removal efficiency. When DSpec was treated by Multivariate Curve Resolution (MCR) analysis for providing chemometric data (DChem), it found ATZ removal and hydroxyatrazine (HAT) formation statistically equal to DChro ( $t$-test, $p=0.05$ ). After unraveling the ATZ degradation mechanism using Spec-Chem, a new hypothesis for the kinetic calculation of ATZ degradation was presented, where the concentrations of ATZ and HAT were used to find $k$ and $\mathrm{R}^{2}$ values representative for the ATZ degradation mechanism. The values found for $k$ were compatible with the literature under similar conditions of ATZ degradation and the linear correlation coefficients $\left(R^{2}=0.99\right)$ showed an optimal fit for the proposed hypothesis. Thus, Spec-Chem was successfully applied to unravel the mechanism of photocatalytic degradation of ATZ in the presence of $\mathrm{TiO}_{2}$, while $k$ was obtained by the new hypothesis proposed that considered ATZ and HAT concentration as parameters of kinect interest. Therefore, the importance of monitoring quantitatively ATZ and HAT were provided in this study, providing new information for the scientific community.

\section{Introduction}

ATZ is an agricultural herbicide widely used in the world and which has attracted the attention of the scientific community due to its presence in environmental ecosystems (Wang et al. 2016; FernándezDomene et al. 2018; Rodrigues et al. 2018; Weber et al. 2018). It is also listed as an emerging contaminant due to its resistance to natural degradation and when oxidized by unconventional processes it forms by-products that are also known to be toxic (Klementová et al. 2019). Due to this toxicity, the studies cannot be limited to only looking for efficient ATZ removal technologies without showing due concern for the by-products formed. Numerous studies involving the ATZ degradation have achieved promising results to remedy this pollutant, but by-products are often ignored and when monitored, the authors adopt a purely qualitative approach (Jiang et al. 2020; Majhi et al. 2020; Zhang et al. 2021). HAT has been reported as a major by-product in the ATZ degradation mechanism, which, due to its low toxicity, is preferred to compose the reaction medium when complete mineralization is not achieved (Moreira et al. 2017; He et al. 2019b).

As the conventional physicochemical/biological treatment processes are inefficient for ATZ degradation, studies that approach homogeneous/heterogeneous photocatalysis are widely found in the literature (Moreira et al. 2017; He et al. 2019a). Photocatalysts such as $\mathrm{Nb}_{2} \mathrm{O}_{5}, \mathrm{ZnO}$, and especially $\mathrm{TiO}_{2}$ are extensively investigated for the environmental remediation of ATZ and other emerging contaminants 
under different operating conditions (Samsudin et al. 2016; Souza et al. 2016; Truc et al. 2019; Paris et al. 2020). To obtain materials with optimized photocatalytic properties, different synthetic methods are employed leading to materials with different properties and catalytical activity (Mohseni-Salehi et al. 2018; Moreira et al. 2020a). Pure $\mathrm{TiO}_{2}$, which is one of the most investigated photocatalysts in the anatase crystalline phase, is well known due to its photoactivity in the UV region (Moreira et al. 2020a). Thus, synthetic methods that use a reduced amount of reagents, steps, and processing time are advantageous, environmentally friendly, and desirable for the production of this material for application in heterogeneous photocatalysis (Gupta and Tripathi 2012)

It turns out that the application of heterogeneous photocatalysis has focused on investigating the properties of the materials, leaving in the background the discussion about the influence of these properties on the degradation mechanism and by-product formation (Gupta and Tripathi 2012; Moyet et al. 2018). Consequently, the information obtained in the photocatalysis studies is generally limited only to the contaminant being degraded, while information about the formation of by-products is little discussed (Khavar et al. 2018; He et al. 2019b). The practical consequence of this approach, which disregards the by-products influence on the degradation mechanism, is directly related to the degradation kinetics of the main contaminant. Different studies have already confirmed that the by-products act as competitors in the pollutant degradation mechanism and therefore, they must be considered in calculations of kinetic constant $(k)$, which is a parameter widely used to conclude on the new technologies' efficiency of environmental remediation (Paris et al. 2020; Malafatti et al. 2020). In the case of ATZ, a search in the current literature clearly shows that the kinetic constants are calculated considering only the initial and final concentrations of ATZ at different degradation times, while by-products, especially HAT, are completely ignored (Majhi et al. 2020; Zhang et al. 2021; Li et al. 2021). The main problem with this adoption is that the kinetic calculations are not representative of the reaction system as a whole and, therefore, it is necessary to advance scientifically to give due attention to the by-products present in the reactional medium.

Also, when these by-products are known and monitored, the understanding of the photocatalytic mechanism of different materials is expanded (Chen et al. 2018; Moreira et al. 2020b). However, this approach, which considers by-products as important as the main contaminant, demands accessible and efficient analytical tools for quantitative monitoring. In this context, analytical techniques most used in ATZ photodegradation studies are chromatography and UV-Vis spectrophotometry (Parmar and Sharma 2016; Moreira et al. 2017; Paris et al. 2020), being chromatography the preferred one for the quantification of ATZ and its by-products (Chen et al. 2018; Khavar et al. 2018). However, chromatography presents important drawbacks such as significant organic solvents consumption and production of chemical residues, as well as a time-consuming execution and demand for skilled labor. For example, Chen et al. (2018) reported that the HPLC analysis of 164 samples of photodegraded ATZ solutions required $137 \mathrm{~h}$ of instrumental use and generated $8.2 \mathrm{~L}$ of residues.

On the other hand, spectrophotometric measurements are fast and of simple operation, easily available Loading [MathJax]/jax/output/CommonHTML/jax.js ince a negligible amount of chemical residue is produced 
after the analytical procedure. UV-Vis spectrophotometry has been used in studies of photocatalytic degradation of ATZ (Moyet et al. 2018; Rincón Joya et al. 2019). However, the use of the molecular absorption spectra of ATZ and its by-products in ATZ photodegradation studies shows some limitations related to spectral interference (Martins et al. 2016; Moreira et al. 2017). HAT results from ATZ oxidation due to the formation of hydroxyl radicals in the reaction medium, which was used to prove the photocatalytic activity of numerous materials (Samsudin et al. 2015; Jamil et al. 2018; He et al. 2019a). However, HAT and other by-products exhibit high molar absorptivity in the absorption band of ATZ (peaked at $222 \mathrm{~nm}$ ), limiting the use of molecular absorption spectrum for monitoring ATZ photodegradation and possibly masking the real efficiency of the photocatalysts already evaluated (Bakar and Ribeiro 2016; Jamil et al. 2018; Rincón Joya et al. 2019; Paris et al. 2020)

The application of chemometric tools such as the Multivariate Curve Resolution (MCR) has proven to be efficient for solving spectral mixtures (Mazivila et al. 2019). As MCR allows to estimate the contribution of each component in the absorption spectrum, the compounds that integrate the spectral mixture can be identified and quantified (Ruckebusch and Blanchet 2013; Ghaffari et al. 2018). As successful examples, MCR allowed to understand the methanol electrooxidation process (Silva et al. 2019), and the determination of different analytes in foods, pharmaceuticals and other products (Arancibia et al. 2014; Fuentes et al. 2015). In fact, with a focus on the development of analytical methods in recent years (Parmar and Sharma 2016), chemometric techniques have been little explored in monitoring photodegradation processes, especially ATZ (Zhang and Pan 2011; Khanmohammadi et al. 2014; Martins et al. 2016; Souza et al. 2016). In one of the few studies found in the literature, the electrochemical degradation mechanism of ATZ was accompanied by spectrophotometry to detail the electrochemical activity of the electrode, while the mechanisms of degradation and by-product formation were not discussed in depth (Souza et al. 2016). Therefore, the use of UV-Vis spectrophotometry coupled to chemometric analysis is a suitable tool for monitoring ATZ and HAT in the context of photodegradation studies.

In this work we investigated the use of MCR, particularly the Multivariate Curve Resolution-Alternating Least Squares (MCR-ALS) algorithm, in the resolution of molecular absorption spectra of ATZ solutions along with photolytic or photocatalytic degradation experiments under UV light radiation. The assays were performed with ATZ solutions at different concentrations. $\mathrm{TiO}_{2}$ was applied as photocatalyst and the possible influence of this heterogeneous system in the formation of by-products was evaluated. Finally, the chemometric approach was validated against chromatographic analysis, while ATZ removal rate (\%), HAT formation (\%), and a new hypothesis for calculating ATZ kinetic constant were discussed based on the concentration of ATZ and HAT, showing the importance that HAT exhibits on the degradation mechanism and kinetics process.

\section{Experimental}

\section{Nanomaterial synthesis}


In a $25 \mathrm{~mL}$ beaker were added $8 \mathrm{~mL}$ of a $20 \%\left(\mathrm{v} \mathrm{v}^{-1}\right)$ isopropanol solution (Sigma Aldrich, $99 \%$ ) and 1.68 $\mathrm{mL}$ of titanium isopropoxide (Sigma Aldrich, 97\%). The mixture was kept under magnetic stirring for 15 min and then transferred to a microwave discharge electrodeless mercury lamp [Hg-MDEL (UMEX GmbH Dresden, Germany)]. Details of Hg-MDEL can be obtained from Moreira et al. $(2018,2019)$. The Hg-MDEL containing the mixture was taken to a microwave equipment MARS 6, $220 \mathrm{~V}, 60 \mathrm{~Hz}$ (CEM, Matthews, NC, USA) and irradiated for 20 min under microwave power of $100 \mathrm{~W}$, reaching a final temperature of $86^{\circ} \mathrm{C}$. After cooling, the precipitate was dried at $50^{\circ} \mathrm{C}$ for $12 \mathrm{~h}$ and divided into 2 equivalent portions. To investigate the effect of the heat treatment temperature, one portion was heated at a rate of $5^{\circ} \mathrm{C} \mathrm{min}-1$ to $400{ }^{\circ} \mathrm{C}$ and maintained for 2 hours, while the other portion was not heat treated. For clarity, Ti_50 and Ti_400 correspond to the nanomaterials obtained after heat treatment of $50^{\circ} \mathrm{C}$ or $400{ }^{\circ} \mathrm{C}$, respectively.

The crystallinity of powders was analyzed by X-ray diffraction (XRD), using a diffractometer (XRD-6000, Shimadzu ${ }^{\circledR}$, Cu ka irradiation, $\lambda=1.54 \AA$, continuous scan, step $0.02^{\circ}$, scan rate $0.5^{\circ} \mathrm{min}^{-1}$, receiving slit $0.3 \mathrm{~mm}$ ) with a $2 \theta$ range from $10^{\circ}$ to $70^{\circ}$. The Scherrer equation was applied to estimate the crystallite size (Muniz et al. 2016). Diffuse reflectance UV-vis spectra were obtained using a UV-Vis spectrophotometer with integrating sphere (ISR-2600 Plus, Shimadzu), applying the range of 200-800 $\mathrm{nm}$. Here, the bandgap energy (Eg) was calculated according to the Kubelka-Munk model (López and Gómez 2012).

\section{Photodegradation assays}

\section{Reagents and solutions}

The $200 \mathrm{mg} \mathrm{L}^{-1}$ stock solutions of atrazine (ATZ), hydroxyatrazine (HAT), desethyl-hydroxyatrazine (DEHAT), desisopropryl-hydroxyatrazine (DIHAT), desethyl-atrazine (DEAT), or desisopropyl-atrazine (DIAT) were prepared from the dissolution of the pure salt (all Sigma-Aldrich reagents, St. Louis, MO, USA) according to the description shown in Moreira et al. (Moreira et al. 2017). Formic acid (98\%, Sigma Aldrich, St. Louis, MO, USA) and HPLC-grade acetonitrile (Sigma-Aldrich, St. Louis, MO, USA) was used for the preparation of the solutions and processes related to chromatographic analysis. All solutions were prepared from analytical grade chemical products and ultra-pure water at $18.0 \mathrm{M} \Omega \mathrm{cm}$ minimal resistivity, in a Milli-Q Plus system (Millipore, Bedford, MA, USA). All solutions were stored in high-density polypropylene flasks (Nalgene ${ }^{\circledR}$, Rochester, NY, USA) and maintained refrigerated.

\section{Photolytic and photocatalytic assays}

The photolytic assays were performed and the results of the chemometric treatment were compared to the obtained by chromatography, while the data obtained in the photocatalytic experiments were treated only by MCR-ALS. ATZ photolytic degradation in the UV region was carried out in a wooden reactor as described by Moreira et al. (2018), at a controlled temperature of $20^{\circ} \mathrm{C}$. Here, $10 \mathrm{~mL}$ of ATZ solution (3.0, 5.0 , or $10.0 \mathrm{mg} \mathrm{L}^{-1}$ ) were added to $50 \mathrm{~mL}$ beaker under continuously shaking. The solutions were firstly irradiated at $5 \mathrm{~min}$ intervals up to $30 \mathrm{~min}$, followed by $10 \mathrm{~min}$ intervals up to $60 \mathrm{~min}$, totaling 30 samples. 
During the photodegradation, aliquots were collected and submitted to analysis by HPLC with UV detection (HPLC-UV) and UV-Vis spectrophotometry.

ATZ photocatalytic degradation in presence of $\mathrm{TiO}_{2}$ was conducted in the same way as described for the photolytic assays. The only difference is the previous dispersion of $5 \mathrm{mg}$ of the material in $10 \mathrm{~mL}$ of the ATZ solution (3.0, 5.0, or $\left.10 \mathrm{mg} \mathrm{L}^{-1}\right)$. Before being irradiated at the conditions previously described, all samples were kept for $30 \mathrm{~min}$ in the dark to promote the adsorption equilibrium. Before the spectrophotometric measurement, each aliquot was filtered through a $0.45 \mu \mathrm{m}$ membrane for removal of the suspended material. The photocatalytic experiments were performed to investigate the possible influence of the heterogeneous system in the ATZ degradation mechanism using UV-Vis spectrophotometry aided by chemometrics.

\section{Chemical analysis}

Spectrophotometric analyzes were conducted on a UV-Vis-NIR spectrophotometer (Cary, 5E® spectrometer) operating in the wavelength scanning mode $\left(500 \mathrm{~nm} \mathrm{~min}{ }^{-1}\right)$. Here, a $3 \mathrm{~mL}$ aliquot of the sample was transferred to a quartz cuvette and scanned in the range of 200 to $350 \mathrm{~nm}$.

Chromatographic analyses were performed using an HPLC UV (Agilent 1220 Infinity LC), detection at 222 $\mathrm{nm}$ and a chromatography column Zorbax Eclipse Plus C18 set to $250 \times 4.6 \mathrm{~mm}, 5 \mu \mathrm{m}$. The mobile phase employed acetonitrile (ACN), formic acid $0.001 \% \mathrm{v} \mathrm{v}^{-1}(A)$, and chromatographic conditions were represented by the elution gradient $\left(v v^{-1}\right)$ : 0 to 2 min, $5 \%(A C N) / 95 \%(A) ; 2$ to 4 min, 30\% (ACN) / 70\% A; 4 to $6 \mathrm{~min}, 50 \%(\mathrm{ACN}) / 50 \%$ A; 6 to $10 \mathrm{~min}, 80 \%(\mathrm{ACN}) / 20 \%(\mathrm{~A}), 10$ to $11 \mathrm{~min}, 5 \%(\mathrm{ACN}) / 95 \%(\mathrm{~A})$ mobile phase flow rate $1 \mathrm{~mL} \mathrm{~min}{ }^{-1}$, and control temperature $30^{\circ} \mathrm{C}$. Chromatographic data processing was controlled by EZChrom Agilent OpenLAB Chromatography Data System Software (CDS). Calibration curve was used for quantification (details in Supplementary Information).

\section{Data processing and analysis}

Chromatographic analyzes were performed in triplicate to find the ATZ or HAT concentration $\left(\mathrm{mg} \mathrm{L}^{-1}\right)$ of all samples subjected to photolytic degradation, totaling 90 analyzes. For each set of samples $(n=10$ for each initial concentration of ATZ), the $\mathrm{C} / \mathrm{C}_{0}$ ratios of ATZ or HAT were calculated and normalized by their highest value. Therefore, for each initial concentration of ATZ, one degradation profile (ATZ) and one formation profile (HAT) were obtained, totaling three profiles for ATZ and three profiles for HAT. Finally, to summarize the three profiles of ATZ or HAT in a single profile each, the mean and standard deviation for each degradation time were calculated.

In the spectrophotometric analyzes, the spectral profile (200 to $350 \mathrm{~nm}$ interval) in each degradation time was obtained for the samples degraded photolytically and photocatalytically, totaling 60 analyzes. Here, the data were assumed in terms of absorbance (Abs) in $222 \mathrm{~nm}$ for ATZ and $238 \mathrm{~nm}$ for HAT to calculate $\mathrm{Abs} / \mathrm{Abs}_{\mathrm{O}}$ ratios. Obtaining ATZ degradation profiles and HAT formation followed the procedures adopted 
for chromatographic data. At the end, a single profile for ATZ (degradation) and HAT (formation) were obtained by averaging the normalized Abs/Abs, values, together with the standard deviation.

MCR was performed on each single 10『301 matrix $(X)$ containing the UV-Vis spectra obtained for the degradation of each ATZ concentration $\left(3,5\right.$, and $\left.10 \mathrm{mg} \mathrm{L}^{-1}\right)$. The rows of $X$ contain the spectra collected at different process times and the columns are kinetic profiles at different wavelengths. The bilinear decomposition is performed on $\mathrm{X}$ according to the expression:

\section{$X=C^{\top}+E(1)$}

in which the columns of $\mathrm{C}$ contain the change as a function of time of the relative concentration of each resolved compound (kinect profiles), the columns of $S$ contain their related spectra, and $E$ is a residual matrix with the unmodeled data variance. Decomposition of $X$ is achieved by an iterative alternating least-squares (ALS) optimization procedure until $\mathrm{CS}^{\top}$ minimizes as much as possible the error in the reproduction of the original data set, $X$.

ALS is performed under suitable constraints, which also help the algorithm to provide solutions with physical meaning. The applied constraints were non-negativity in the concentration and spectra profiles, and closure constraints in $\mathrm{C}$ matrix. The validity of this constraint was confirmed by the similar fits obtained when the closure constraint was applied or not. MCR-ALS needs initialization with the number of components, which was obtained from singular value decomposition analysis of X. Following, simpleto-use interactive self-modeling mixture analysis was used to find an initial estimate of pure spectra of the components with $10 \%$ of noise allowed. The percentage of lack of fit (\% lof) and the explained variance $\left(R^{2}\right)$ were the parameters used to evaluate the fit quality of the MCR-ALS results. More information regarding the theory and execution of MCR-ALS can be found elsewhere (De Juan et al. 2014). All data analysis was carried out within a Matlab® environment using the MCR-ALS routine implemented in the MCR-ALS GUI (Jaumot et al. 2015).

As in the chromatographic and spectrophotometric analyses, for each initial ATZ concentration, one degradation profile (ATZ) and one formation profile (HAT) were obtained from the chemometric treatment, resulting in three profiles for each compound. The ratios were also calculated, normalized, and used to obtain a single profile of degradation (ATZ) and formation (HAT) employing the averages and standard deviations. For clarity, chromatographic profiles were identified as DChro, chemometric profiles as DChem, and spectrophotometric profiles as DSpec. DChem data was compared to DChro data by applying a t-test $(p=0.05)$.

\section{Results And Discussion}

\section{Nanomaterials characterization}


In Fig. $1 \mathrm{a}$ it is shown the X-ray diffraction pattern of the Ti_50 and Ti_400 samples, which presents characteristic diffraction peaks for both anatase and brookite $\mathrm{TiO}_{2}$ crystalline phases.

The nanoparticles show peaks at $25.34^{\circ}(111), 37.94^{\circ}(004), 47.94^{\circ}(200), 54.40^{\circ}(105) /(211), 62.90^{\circ}$ (204), and $68,67^{\circ}$ (116) assigned to anatase phase according to JCPDS 21-1272. Further, a low amount of the brookite phase is identified by the presence of the diffraction peaks at $30.68^{\circ}(121), 40.22^{\circ}(022)$, $42.46^{\circ}(221), 46.00^{\circ}(032)$, and $60.00^{\circ}$ (123), in agreement with the JCPDS sheet 29-1360 (Di Paola et al. 2008; Mehraz et al. 2019). Moreover, the broad diffraction peaks indicate a very small size crystallite, which can be estimated by the Scherrer equation. Considering the diffraction peak at $25.34^{\circ}$ ascribed to the anatase phase it is calculated average crystallite size of $8.39 \mathrm{~nm}$ (Zhao et al. 2007; Mehraz et al. 2019).

Table 1

- Crystallographic parameters of Ti_400 sample.

\begin{tabular}{|llllll|}
\hline $\begin{array}{l}\text { Crystallographic } \\
\text { phase }\end{array}$ & $\begin{array}{l}\mathbf{2 \theta} \\
(\mathbf{d e g r e e})^{\#}\end{array}$ & $\mathbf{d}(\AA) *$ & $\begin{array}{l}\text { Intensity } \\
\text { (counts) }\end{array}$ & $\begin{array}{l}\text { Observed } \\
\text { ratio }\end{array}$ & $\begin{array}{l}\text { Expected } \\
\text { ratio }\end{array}$ \\
\hline Anatase & 25.34 & 3.5119 & 1341 & 100 & 100 \\
\hline Brookite & 30.68 & 2.9117 & 115 & 9 & 90 \\
\hline Anatase & 37.94 & 2.3696 & 366 & 27 & 20 \\
\hline Brookite & 40.22 & 2.2403 & 55 & 4 & 18 \\
\hline Brookite & 42.46 & 2.1272 & 35 & 7 & 16 \\
\hline Brookite & 46.00 & 1.9714 & 93 & 35 & 16 \\
\hline Anatase & 47.94 & 1.8960 & 476 & 30 & 20 \\
\hline Anatase & 54.40 & 1.6852 & 405 & 3 & 7 \\
\hline Brookite & 60.00 & 1.5406 & 46 & 17 & 14 \\
\hline Anatase & 62.90 & 1.4763 & 229 & 8 & 6 \\
\hline Anatase & 68.67 & 1.3657 & 101 & 75 \\
\hline \# 2 $\theta=$ Angle of the diffraction peak; * $\mathrm{d}=$ Distance between atomic planes, & \\
\hline
\end{tabular}

It is worth remembering that the Scherrer equation is an approximation and not an accurate method for estimating the size of crystalline nanoparticles (Kibasomba et al. 2018). However, this estimation suggests a nanometric nature of the materials, indicating an important characteristic of semiconductors applied in heterogeneous photocatalysis (Moreira et al. 2020a). As the main purpose of the paper is to monitor the ATZ photolysis and photocatalysis using the chemometric approach for investigating degradation mechanism, the use of transmission electron microscopy to measure the nanoparticle size was dismissed. Figure $1 \mathrm{~b}$ shows the Tauc plot and the bandgap energy calculated for the Ti_400 sample, Loading [MathJax]/jax/output/CommonHTML/jax.js talline phase observed in the X-ray diffractograms. The 
Ti_400 presents an indirect bandgap of $3.18 \mathrm{eV}$, which is expected for anatase $\mathrm{TiO}_{2}$ and is in accordance with the literature (Beranek 2011; Tripathi et al. 2013). Numerous studies show that $\mathrm{TiO}_{2}$ anatase is photoactive and widely used in studies of heterogeneous photocatalysis (Fang et al. 2017; Moreira et al. 2020a). Also, its nanometric nature and bandgap close to $3.18 \mathrm{eV}$ are two important properties for the application of $\mathrm{TiO}_{2}$ as a photocatalyst (Di Paola et al. 2008). Thus, the synthesis method applied in this study proved to be efficient to achieve these characteristics of $\mathrm{TiO}_{2}$ after a short synthesis time (20 min) followed by heat treatment at $400{ }^{\circ} \mathrm{C}$ for $2 \mathrm{~h}$. Therefore, this material (Ti_400) was applied in the photocatalytic degradation studies of ATZ to investigate the influence of the heterogeneous process in the degradation mechanism using UV-Vis spectrophotometry aided by chemometrics.

\section{Photolytic degradation of ATZ}

Figure 2 showed the molecular absorption spectra (Fig. 2a) and the chromatographic profiles (Fig. 2b) obtained at different time intervals from the ATZ photolytic degradation under UV irradiation.

The peak centered at $222 \mathrm{~nm}$ (Fig. 2a), which can be attributed to ATZ, exhibited a decreasing absorbance as the irradiation time increased, reaching its lowest value at about 0.4 u.a. In contrast, the peak centered at $238 \mathrm{~nm}$, which can be attributed to HAT, exhibited an increase in absorbance, confirming the conversion of ATZ to HAT during the photochemical step (Moreira et al. 2016). Corroborating with the molecular absorption results, the chromatograms (Fig. 2b) show the HAT formation as a result of ATZ degradation. However, while DChro indicated 95\% ATZ removal in 30 min, DSpec indicated only 57\% removal at the same time interval. Also, at the maximum irradiation time (60 min), ATZ removal remained at $57 \%$ according to DSpec, in disagreement with the $99 \%$ ATZ removal shown by DChro. It is also worth mentioning that the results of the chromatographic analysis do not show the formation of other byproducts monitored in this study [DEAT, DIAT, DEHAT, and DIHAT (Fig. S1)]. Thus, both the amount and the identity of the compounds that participate in the photolytic degradation process are corresponding by the two analytical techniques used.

The first-order kinetic model (Eq. 1) that considers the variation in ATZ concentration as a function of degradation time was used to calculate the kinetic constant $(k)$ and its linear correlation coefficient $\left(R^{2}\right)$ (Samsudin et al. 2015).

$\ln \left(\frac{A T Z_{\text {final }}}{A T Z_{\text {initial }}}\right)=-k t$ Eq. 1

The $k$ and $\mathrm{R}^{2}$ mean values for ATZ at different concentrations were $k=0.113 \pm 0.012 \mathrm{~min}^{-1} / \mathrm{R}^{2}=0.992 \pm$ 0.001 for DChro and $k=0.021 \pm 0.004 \mathrm{~min}^{-1} / \mathrm{R}^{2}=0.806 \pm 0.045$ for DSpec, which confirms the inapplicability of DSpec in its conventional use. Here, a difference of $85 \%$ was obtained for the kinetic constants, while $\mathrm{R}^{2}$ showed a linear correlation only for DChro. Evidently, these appreciable differences of $38 \%$ in the ATZ removal and $85 \%$ in the kinetic constant help to understand why chromatography is the Loading [MathJax]/jax/output/CommonHTML/jax.js todegradation of organic compounds when compared to 
spectrophotometry (Singh et al. 2018). The accuracy of DSpec was significantly impaired due to the spectral interferences between ATZ and HAT present in the same solution. According to Moreira et al. (2017), the molar absorptivity coefficient for some by-products is greater than that of ATZ at $222 \mathrm{~nm}$, which justifies the limitation of the drop in absorbance, as shown in Fig. 2(a). In this sense, to overcome the spectral interferences and improve the DSpec reliability, a chemometric data treatment (DChem) based on MCR-ALS was performed.

MCR-ALS was performed on each matrix obtained from the degradation of the different ATZ concentrations. The execution in each matrix was performed considering that the photodegradation process could be dependent on the ATZ concentration, which could result in a different number of species in each experiment as a result of the MCR-ALS analysis. However, initial SVD analysis showed for each experiment the presence of only two species during the photodegradation process. Figure 3 shows the UV-Vis spectra from $S^{\top}$ matrix and the kinetic profiles from $\mathrm{C}$ matrix (concentration profiles) obtained by MCR-ALS. Explained variances and lack of fit values are, respectively, $2.00 \%$ and $99.96 \%$ for $3 \mathrm{mg} \mathrm{L}^{-1}$ ATZ, $1.75 \%$ and $99.97 \%$ for $5 \mathrm{mg} \mathrm{L}^{-1}$ ATZ, and $1.24 \%$ and $99.98 \%$ for $10 \mathrm{mg} \mathrm{L}^{-1}$ ATZ. These values indicate that excellent fits were obtained.

The pure spectra obtained from the decomposition of $X$ is compared to the spectra obtained from standard solutions of ATZ and HAT. As can be seen, component 1 obtained from the MCR-ALS analysis has a spectrum very similar to the ATZ spectrum, while component 2 resembles the HAT spectrum. The same number of species and spectra obtained for all ATZ concentrations evaluated show the photodegradation process followed the same pathway despite the change on ATZ concentration, also presenting similar kinect profiles for ATZ consumption and HAT formation. One can see that ATZ concentration decreased to half its initial concentration right before 10 min of UV-light irradiation and continued being reduced until disappearing afterward, in agreement with the results obtained from chromatographic analysis (Fig. 3b). Simultaneously, the kinetic profile corresponding to HAT formation appeared at the beginning of the experiment reaching its maximum value at the end of the time frame of the experiment.

Figure 4 shows the ATZ degradation curves (Fig. 4a) and HAT formation (Fig. 4b) when the DChro, DSpec, and DChem were normalized and compared. It is noted that the graphic profile of the DChem was similar to DChro and significantly improved compared to DSpec. Moreover, the statistical analysis assuming a $95 \%$ confidence level (t-test) confirmed that there is no significant difference between the DChro and DChem results for ATZ degradation and HAT formation. However, the comparative data between DChro and DSpec showed a significant difference for the degradation of ATZ and HAT production, reinforcing the inapplicability of DSpec in its conventional use.

DChro and DChem showed an ATZ removal of $83 \pm 3 \%$ in 20 min, while DSpec showed removal of $53 \pm$ $1 \%$ in the same time frame. Also, this removal reached $100 \pm 0.2 \%$ and $93 \pm 5 \%$ in 60 min to the DChro and the DChem, respectively, while the DSpec exhibits only $55 \pm 3 \%$ at the same conditions. Here, the data Loading [MathJax]/jax/output/CommonHTML/jax.js $]$ Z degradation profile, which was more pronounced up to 20 
min. This behavior in the degradation mechanism of emerging contaminants has already been shown in other studies, and the by-products when formed, act as competitors in the degradation process (Moreira et al. 2019). Thus, as HAT was formed, a radiation portion and possible oxidizing agents are consumed by this compound (especially after $20 \mathrm{~min}$ ), affecting the ATZ removal. Therefore, DChro and DChem were limited to $20 \mathrm{~min}$ to calculate the kinetic constant $(k)$ and the linear correlation coefficient $\left(\mathrm{R}^{2}\right)$ of ATZ degradation. The values found were $k=0.116 \pm 0.004 \mathrm{~min}^{-1} / \mathrm{R}^{2}=0.996 \pm 0.005$ for DChro and $k=$ $0.093 \pm 0.002 \mathrm{~min}^{-1} / \mathrm{R}^{2}=0.998 \pm 0.001$ for DChem.

The results show that the difference between the $k$ values is $<20 \%$, while $\mathrm{R}^{2}$ values indicate the good fit of the theoretical model to the experimental data. These results and the similarity between the kinetic profiles verified by the $t$-test confirm the applicability of MCR-ALS in the treatment of molecular absorption spectra in the study of ATZ photodegradation. To highlight the importance of HAT quantitative monitoring and the applicability of MCR-ALS in providing reliable data, a new hypothesis was tested for the calculation of $k$ in this study. The chromatogram of Fig. $2 b$ and the MCR-ALS data in Fig. 3 confirmed HAT as the major by-product formed during ATZ degradation, corroborating with the literature that points out that HAT is present in the first stage of the ATZ degradation mechanism (Moreira et al. 2017; He et al. 2019a). In this way, it is possible to suggest that ATZ is totally converted to HAT in the first minutes of the reaction, which was limited to 20 min due to the reasons explained above. Thus, while Eq. 2 shows the conversion stoichiometry from $A T Z\left(\mathrm{C}_{8} \mathrm{H}_{14} \mathrm{CIN}_{5}\right)$ to HAT $\left(\mathrm{C}_{8} \mathrm{H}_{15} \mathrm{NO}\right)$, the set of Eq. 3 to 6 presents the mathematical hypothesis for calculating $k$.

$\mathrm{C}_{8} \mathrm{H}_{14} \mathrm{ClN}_{5}+\mathrm{H}_{2} \mathrm{O}+\mathrm{h} \otimes \diamond \mathrm{C}_{8} \mathrm{H}_{15} \mathrm{~N}_{5} \mathrm{O}+\mathrm{HCl}$ Eq. 2

Eq. 2 shows that the conversion stoichiometry of ATZ $\diamond$ HAT is 1:1, and therefore the valid equality is

$A T Z_{\text {degraded }}=H A T_{\text {formed }}$ Eq. 3

Thus,

$A T Z_{\text {final }}=A T Z_{\text {initial }}-A T Z_{\text {degraded }}$ Eq. 4

Replacing Eq. 3 in Eq. 4, we have

$A T Z_{\text {final }}=A T Z_{\text {initial }}-H A T_{\text {formed }}$ Eq. 5

Finally replacing Eq. 5 in Eq. 1, the new hypothesis for calculating k is given by Eq. 6

$\ln \left(\frac{A T Z_{\text {intial }}-H A T_{\text {formed }}}{A T Z_{\text {initial }}}\right)=-k t$ Eq. 6

Eq. 6 represents an advance for obtaining $k$, since, in most of this type of study, by-products such as HAT Loading [MathJax]/jax/output/CommonHTML/jax.js the degradation mechanism. Therefore, the new values of $k$ 
and $\mathrm{R}^{2}$ using the DSpec, DChro, and DChem data were shown in Table 2.

Table 2

Kinetic constants calculated by the conventional approach (Eq. 1) and by the new proposal (Eq. 6).

\begin{tabular}{|llll|}
\hline $\begin{array}{l}\text { Data } \\
\text { source }\end{array}$ & $\begin{array}{l}\boldsymbol{k}\left(\mathrm{min}^{-1}\right) \text { and } \mathrm{R}^{2} \text { obtained by } \\
\mathrm{Eq} \mathbf{1}\end{array}$ & $\begin{array}{l}\boldsymbol{k}\left(\mathrm{min}^{-1}\right) \text { and } \mathrm{R}^{2} \text { obtained by } \\
\mathrm{Eq} .\end{array}$ & $\begin{array}{l}\text { Difference of } \boldsymbol{k} \\
\text { between } \\
\text { Eq. } 1 \text { and Eq. } 6\end{array}$ \\
\hline DSpec & $0.038 / 0.979$ & $0.069 / 0.979$ & $45 \%$ \\
\hline DChro & $0.116 / 0.996$ & $0.099 / 0.995$ & $15 \%$ \\
\hline DChem & $0.093 / 0.998$ & $0.080 / 0.985$ & $14 \%$ \\
\hline
\end{tabular}

The new values show a significant increase from $k$ to DSpec, evidencing the significant influence that HAT exerts on the ATZ degradation kinetic mechanism and, therefore, HAT cannot be ignored. On the other hand, the $k$ and $\mathrm{R}^{2}$ values found for DChro and DChem show a slight decrease, while the compatibility between these was maintained, as shown by the differences $k$ in the order of $15 \%$ and $14 \%$, respectively. Also, this observed decrease in $k$ values for DChro and DChem is justified by the greater capacity that these techniques exhibit in providing quantitative data closer to reality for ATZ and HAT. Especially for HAT, Fig. $2 b$ showed some unknown peaks, which may be the result of the HAT degradation, causing a small deviation to the applicability of Eq. 6 . However, it is worth noting that when limiting the data treatment to 20 min, these deviations were not significant, which is confirmed by the good $R^{2}$ values obtained for DChro and DChem, confirming the reaction stoichiometry is $1: 1$. Thus, it is possible to replace the chromatographic approach by the chemometric one with similar efficiency, while $k$ calculated by Eq. 6 provides a most realistic information for unveiling the ATZ degradation kinetic mechanism.

\section{Photocatalytic degradation of ATZ}

In addition to photolytic studies, the literature broadly addresses heterogeneous photocatalysis for degradation of atrazine and other emerging contaminants (Chen et al. 2018; Moreira et al. 2018; Paris et al. 2020). Thus, this study was expanded to evaluate the application of MCR-ALS in the analysis of the photocatalytic degradation of ATZ in the presence of $\mathrm{TiO}_{2}$. According to the characterization data (Sect. 3.1), Ti_400 was applied for the photocatalytic degradation of ATZ under UV radiation $(254 \mathrm{~nm})$. Figure 5 shows the UV-Vis spectra and the kinetic profiles recovered from MCR-ALS decomposition of the matrices obtained from photocatalytic experiments. Explained variances and lack of fit values are, respectively, $6.94 \%$ and $99.52 \%$ for $3 \mathrm{mg} \mathrm{L}^{-1}$ ATZ, $6.84 \%$ and $99.53 \%$ for $5 \mathrm{mg} \mathrm{L}^{-1}$ ATZ, and $5.49 \%$ and $99.70 \%$ for $10 \mathrm{mg} \mathrm{L}^{-1}$ ATZ. The lack of fit values is higher than those observed for ATZ photolysis, which may be related to the noisier spectra obtained from the photocatalysis experiments caused by a residual amount of $\mathrm{TiO}_{2}$. However, these values still indicate that good fits were obtained. 
As observed for ATZ photolysis, SVD analysis showed the occurrence of only two species during ATZ photodegradation with $\mathrm{TiO}_{2}$ and UV radiation, independent of $A T Z$ concentration. The obtained pure spectra (Fig. 5a) can also be attributed to ATZ and HAT. Kinect profiles for ATZ consumption and HAT formation (Fig. 5b, 5c, and 5d) also show a behavior similar to that observed for ATZ photolysis. However, some important differences have been noticed for the experiments related to the degradation of ATZ at 3 $\mathrm{mg} \mathrm{L}^{-1}$ and $5 \mathrm{mg} \mathrm{L}^{-1}$. In these experiments one can see the concentration of HAT in $\mathrm{t}=0 \mathrm{~s}$ is not null, indicating a possible conversion of ATZ in HAT by the action of the photocatalyst previously to UV radiation. This initial conversion is proportionally higher in the experiment performed with the $3 \mathrm{mg} \mathrm{L}^{-1}$ solution, lower with the $5 \mathrm{mg} \mathrm{L}^{-1}$ solution, and negligible with the $10 \mathrm{mg} \mathrm{L}^{-1}$ solution. Despite this initial photocatalytical activity, the complete removal of ATZ (maximum HAT formation) is observed in the same time frame as observed for ATZ photolysis. Figure 6 shows the ATZ decay curve and HAT formation after the MCR analysis of the molecular absorption spectra.

Applying Eq. 6 to calculate the $k$ representative of the photocatalytic degradation curve of ATZ (Fig. 6a) showed a $k=0.068 \pm 0.008 \mathrm{~min}^{-1} / \mathrm{R}^{2}=0.943 \pm 0.003$, considering a first-order reaction mechanism. This result was approximately $15 \%$ lower than the constant found for the photolytic step $(k=0.083 \pm 0.002$ $\left.\mathrm{min}^{-1} / \mathrm{R}^{2}=0.985 \pm 0.001\right)$. The literature reports that different factors are responsible for influencing the efficiency of the photocatalytic process, highlighting the initial pH of the reaction medium (Bakar and Ribeiro 2016; Moreira et al. 2020b), the mass of the catalyst (He et al. 2019a), and the efficiency of carrying charge on the surface of the material (Truc et al. 2019; Moreira et al. 2020a). As pointed out earlier, the focus of this study was to show that the MCR is applicable to solve molecular absorption spectra in both photolytic and photocatalytic studies, and, therefore, the optimal conditions of degradation have not been investigated. In addition, the $R^{2}=0.943 \pm 0.003$ obtained after the photocatalysis confirmed that the MCR treatment was efficient to achieve a reliable result after the photocatalytic degradation of ATZ.

Corroborating the effective applicability of MCR to solve the photocatalytic degradation of ATZ, Fig. $6 \mathrm{~b}$ showed the formation profile of HAT for photocatalysis. Thus, the lower formation of HAT in the photocatalytic stage corroborates with the lower degradation of ATZ and, therefore, the MCR was efficient to show the correlation in the degradation mechanism. Therefore, after proving the applicability of MCR to solve ATZ molecular absorption spectra in both the photolytic and photocatalytic processes, other gains were highlighted in this study.

\section{Economic and environmental gains associated with the MCR application.}

The applicability of MCR as an analytical tool for monitoring ATZ and HAT after photodegradation was verified in this study. However, the advantages of using this tool have been expanded to highlight its economic and environmental gains compared to chromatographic analysis. The operational parameters of the chemical analyses presented in Sect. 2.2.3 were used to estimate the time required for analysis and the total volume of chemical waste generated (Table 3).

Loading [MathJax]/jax/output/CommonHTML/jax.js

Page $13 / 25$ 
Table 3

- Time required for analysis and total volume of chemical waste generated throughout spectrophotometric or chromatographic analyses in this study.

\begin{tabular}{|llll|}
\hline Analytical method & $\begin{array}{l}\text { Performed analyzes } \\
\text { amount }\end{array}$ & $\begin{array}{l}\text { Time spent in the } \\
\text { analysis * }\end{array}$ & $\begin{array}{l}\text { Residue from the analytical } \\
\text { process }\end{array}$ \\
\hline Chromatographic & $130 * *$ & $24 \mathrm{~h}$ & $1.43 \mathrm{~L} * \star *$ \\
\hline Spectrophotometric & 60 & $0.33 \mathrm{~h}$ & - \\
\hline$*$ Time required for each analysis: Spectrophotometer $=0.33 \mathrm{~min} ; \mathrm{HPLC}=11 \mathrm{~min}$ \\
\hline$* \star 40$ analyzes refer to the calibration curve construction. \\
\hline$* \star *$ Of the total volume of analytical waste, $36 \%$ corresponds to acetonitrile. \\
\hline
\end{tabular}

Table 3 shows that the analysis time demanded by the spectrophotometric measurements represents only $1.5 \%$ of the time demanded by the chromatographic ones to perform the same photodegradation experiment. Moreover, while the chromatographic analysis required a calibration curve, the application of the MCR dispensed this step, without prejudice to the final result. As for chemical waste generation, the spectrophotometric analysis follows by MCR treatment generated only a negligible volume, while a volume of $1.43 \mathrm{~L}$ was produced at the end of the chromatographic analysis. In addition, data can be obtained more quickly by using the MCR, which can be considered environmentally friendly.

\section{Conclusions}

In this study, the use of spectrophotometry and chromatography as analytical tools were investigated to monitor photodegraded ATZ solutions. In 60 min of UV irradiation, the removal of ATZ reached a maximum value of $55 \pm 3 \%$ (DSpec) and $100 \pm 2 \%$ (DChro), showing a difference of $45 \%$ in removal efficiency. The presence of HAT was confirmed by both techniques and its interference in the ATZ absorption band (222 $\mathrm{nm}$ ) was responsible for influencing the removal calculation using the DSpec in its raw form. Thus, the use of MCR was applied to solve the molecular absorption spectra and found the removal of $93 \pm 5 \%$ for ATZ (DChem). Statistical analysis with a $95 \%$ confidence level ( $t$-test) proved that the results found for ATZ and HAT obtained by DChro and DChem are equivalent for photolytic degradation of ATZ. After the validation of DChem, a new hypothesis was considered to calculate the ATZ degradation kinetic constant taking into account the concentrations of ATZ and HAT. Following this new hypothesis, the values of $k$ were: $k=0.069 \mathrm{~min}^{-1} / \mathrm{R}^{2}=0.979$ for DSpec, $k=0.099 \mathrm{~min}^{-1} / \mathrm{R}^{2}=0.995$ for DChro and $k=0.080 \mathrm{~min}^{-1} / \mathrm{R}^{2}=0.985$ for DChem. After validating the MCR-ALS results and the new hypothesis for calculating $k$, these were applied to calculate the $k$ value during the photocatalytic degradation of $A T Z$ in the presence of $\mathrm{TiO}_{2}$. Thus, since it has the highest crystallinity and a bandgap of $3.18 \mathrm{eV}$, the Ti_400 was applied to assess possible interferences in the MCR treatment of the molecular absorption spectra of photodegraded ATZ. Again, MCR was efficient to solve the molecular absorption Loading [MathJax]/jax/output/CommonHTML/jax.js s catalysis (Ti_400), eliminating the use of chromatographic 
analyzes and finding $k=0.068 \mathrm{~min}^{-1} / \mathrm{R}^{2}=0.943$. Further, to obtain the DSpec, no chemical residue from the analytical process was generated and the time required for the analyzes $(0.33 \mathrm{~h})$ was less than the chromatographic analyzes (24h). Thus, a simple, fast, efficient, more accessible, and environmentally friendly procedure was presented to monitor ATZ and HAT in studies of advanced oxidation. Therefore, this study showed that ATZ and HAT can be efficiently monitored using spectrophotometrychemometrics, while the calculation of $k\left(\mathrm{~min}^{-1}\right)$ considering the concentrations of ATZ and HAT is more representative with respect to the ATZ degradation mechanism.

\section{Declarations}

\section{Ethics approval and consent to participate}

Not applicable

\section{Consent for publication}

Not applicable

\section{Availability of data and materials}

The datasets used and analyzed during the current study are available from the corresponding author on reasonable request.

\section{Competing interests}

The authors declare that they have no competing interests.

\section{Funding}

Not applicable

\section{Authors' contributions}

All authors contributed to the study conception and design. Ailton José Moreira: writing and Methodology; Sherlan G. Lemos: Metodology, writing and review; Dyovani Coelho: writing-review and editing; Lucia H. Mascaro and Gian P. G. Freschi: review and editing; Ernesto C. Pereira: writing, conceptualization, supervision. All authors commented on previous versions of the manuscript. All authors read and approved the fnal manuscript.

\section{Acknowledgments}

This work was financially supported by Fundação de Amparo à Pesquisa do Estado de Minas Gerais (Fapemig), Coordenação de Aperfeiçoamento de Pessoal de Nível Superior (CAPES, grant \# 88887.368533/2019-00 and Code \# 001: 88881.068088/2014-01 and Code \# 001), Fundação de Amparo Loading [MathJax]/jax/output/CommonHTML/jax.js 
à Pesquisa do Estado de São Paulo (grants: 2013/07296-2, 2014/50249-8, 2017/11986-5), Conselho Nacional de Desenvolvimento Científico e Tecnológico (CNPq), and Shell..

\section{References}

1. Arancibia JA, Damiani PC, Ibañez GA, Olivier AC (2014) Recent applications of first-and second-order multivariate calibration to analytical chemistry. J AOAC Int 97:39-49. https://doi.org/10.5740/jaoacint.SGEArancibia

2. Bakar SA, Ribeiro C (2016) Low temperature synthesis of N-doped TiO 2 with rice-like morphology through peroxo assisted hydrothermal route: Materials characterization and photocatalytic properties. Appl Surf Sci 377:121-133. https://doi.org/10.1016/j.apsusc.2016.03.137

3. Beranek R (2011) (Photo)electrochemical methods for the determination of the band edge positions of TiO 2-based nanomaterials. Adv Phys Chem 2011:80-83. https://doi.org/10.1155/2011/786759

4. Chen CC, Shaya J, Fan HJ, et al (2018) Silver vanadium oxide materials: Controlled synthesis by hydrothermal method and efficient photocatalytic degradation of atrazine and CV dye. Sep Purif Technol 206:226-238. https://doi.org/10.1016/j.seppur.2018.06.011

5. De Juan A, Jaumot J, Tauler R (2014) Multivariate Curve Resolution (MCR). Solving the mixture analysis problem. Anal Methods 6:4964-4976. https://doi.org/10.1039/c4ay00571f

6. Di Paola A, Cufalo G, Addamo M, et al (2008) Photocatalytic activity of nanocrystalline TiO2 (brookite, rutile and brookite-based) powders prepared by thermohydrolysis of $\mathrm{TiCl} 4$ in aqueous chloride solutions. Colloids Surfaces A Physicochem Eng Asp 317:366-376. https://doi.org/10.1016/j.colsurfa.2007.11.005

7. Fang W, Xing M, Zhang J (2017) Modifications on reduced titanium dioxide photocatalysts: A review. J Photochem Photobiol C Photochem Rev 32:21-39.

https://doi.org/10.1016/j.jphotochemrev.2017.05.003

8. Fernández-Domene RM, Sánchez-Tovar R, Lucas-granados B, et al (2018) Elimination of pesticide atrazine by photoelectrocatalysis using a photoanode based on WO3 nanosheets. Chem Eng J 350:1114-1124. https://doi.org/10.1016/j.cej.2018.06.015

9. Fuentes E, Cid C, Báez ME (2015) Determination of imidacloprid in water samples via photochemically induced fluorescence and second-order multivariate calibration. Talanta 134:8-15. https://doi.org/10.1016/j.talanta.2014.11.017

10. Ghaffari M, Olivieri AC, Abdollahi H (2018) Strategy to Obtain Accurate Analytical Solutions in Second-Order Multivariate Calibration with Curve Resolution Methods. Anal Chem 90:9725-9733. https://doi.org/10.1021/acs.analchem.8b00336

11. Gupta SM, Tripathi M (2012) A review on the synthesis of TiO 2 nanoparticles by solution route. Cent Eur J Chem 10:279-294. https://doi.org/10.2478/s11532-011-0155-y

12. He D, Yang Y, Tang J, et al (2019a) Synergistic effect of TiO 2 -CuWO 4 on the photocatalytic denradation of atrazine Fnvirnn Sci Pollut Res 26:12359-12367. https://doi.org/10.1007/s11356- 
019-04686-1

13. He H, Liu Y, You S, et al (2019b) A review on recent treatment technology for herbicide atrazine in contaminated environment. Int J Environ Res Public Health 16:.

https://doi.org/10.3390/ijerph16245129

14. Jamil TS, Abbas HA, Nasr RA, Vannier RN (2018) Visible light activity of BaFe1-xCux03- $\delta$ as photocatalyst for atrazine degradation. Ecotoxicol Environ Saf 163:620-628.

https://doi.org/10.1016/j.ecoenv.2018.07.106

15. Jaumot J, Juan A De, Tauler R (2015) Chemometrics and Intelligent Laboratory Systems MCR-ALS GUI 2 . 0: New features and applications. Chemom Intell Lab Syst 140:1-12

16. Jiang Z, Li J, Jiang D, et al (2020) Removal of atrazine by biochar-supported zero-valent iron catalyzed persulfate oxidation: Reactivity, radical production and transformation pathway. Environ. Res. 184

17. Khanmohammadi M, Garmarudi AB, Elmizadeh H, Roochi MB (2014) Spectrophotometric evaluation of the photocatalytic degradation of formaldehyde by Fe203-TiO2 nano hybrid. J Ind Eng Chem 20:1841-1844. https://doi.org/10.1016/j.jiec.2013.08.040

18. Khavar AHC, Moussavi G, Mahjoub AR, et al (2018) Synthesis and visible-light photocatalytic activity of In,S-TiO2@rGO nanocomposite for degradation and detoxification of pesticide atrazine in water. Chem Eng J 345:300-311. https://doi.org/10.1016/j.cej.2018.03.095

19. Kibasomba PM, Dhlamini S, Maaza M, et al (2018) Strain and grain size of TiO2 nanoparticles from TEM, Raman spectroscopy and XRD: The revisiting of the Williamson-Hall plot method. Results Phys 9:628-635. https://doi.org/10.1016/j.rinp.2018.03.008

20. Klementová Š, Hornychová L, Šorf M, et al (2019) Toxicity of atrazine and the products of its homogeneous photocatalytic degradation on the aquatic organisms Lemna minor and Daphnia magna. Environ Sci Pollut Res 26:27259-27267. https://doi.org/10.1007/s11356-019-05710-0

21. Li F, Li T, Zhang L, et al (2021) Enhancing photocatalytic performance by direct photo-excited electron transfer from organic pollutants to low-polymerized graphitic carbon nitride with more CNH/NH2 exposure. Appl Catal B Environ 296:120316. https://doi.org/10.1016/j.apcatb.2021.120316

22. López R, Gómez R (2012) Band-gap energy estimation from diffuse reflectance measurements on sol-gel and commercial TiO 2: A comparative study. J Sol-Gel Sci Technol 61:1-7. https://doi.org/10.1007/s10971-011-2582-9

23. Majhi D, Das K, Mishra A, et al (2020) One pot synthesis of CdS/BiOBr/Bi2O2CO3: A novel ternary double Z-scheme heterostructure photocatalyst for efficient degradation of atrazine. Appl Catal B Environ 260:118222. https://doi.org/10.1016/j.apcatb.2019.118222

24. Malafatti JOD, Moreira AJ, Sciena CR, et al (2020) Prozac® removal promoted by HAP:Nb205 nanoparticles system: by-products, mechanism, and cytotoxicity assessment. J Environ Chem Eng 104820. https://doi.org/10.1016/j.jece.2020.104820

25. Martins EC, Melo VDF, Abate G (2016) Evaluation of flow injection analysis method with Loading [MathJax]/jax/output/CommonHTML/jax.js termination of atrazine in soil extracts. J Environ Sci Heal - 
Part B Pestic Food Contam Agric Wastes 51:609-615.

https://doi.org/10.1080/03601234.2016.1181906

26. Mazivila SJ, Ricardo IA, Leitão JMM, Esteves da Silva JCG (2019) A review on advanced oxidation processes: From classical to new perspectives coupled to two- and multi-way calibration strategies to monitor degradation of contaminants in environmental samples. Trends Environ Anal Chem 24:110. https://doi.org/10.1016/j.teac.2019.e00072

27. Mehraz S, Kongsong P, Taleb A, et al (2019) Large scale and facile synthesis of Sn doped TiO2 aggregates using hydrothermal synthesis. Sol Energy Mater Sol Cells 189:254-262. https://doi.org/10.1016/j.solmat.2017.06.048

28. Mohseni-Salehi MS, Taheri-Nassaj E, Hosseini-Zori M (2018) Study on cytotoxicity and photocatalytic properties of different titania/hydroxyapatite nanocomposites prepared with a combination of sol-gel and precipitation methods. Res Chem Intermed 44:1945-1962. https://doi.org/10.1007/s11164-017-3208-9

29. Moreira A, Borges A, de Sousa B, et al (2018) Photodegradation of Fluoxetine Applying Different Photolytic Reactors: Evaluation of the Process Efficiency and Mechanism. J Braz Chem Soc 30:1010-1024. https://doi.org/10.21577/0103-5053.20180250

30. Moreira AJ, Borges AC, de Souza BB, et al (2019) Microwave discharge electrodeless mercury lamp (Hg-MDEL): An energetic, mechanistic and kinetic approach to the degradation of Prozac®. J Environ Chem Eng 7:102916. https://doi.org/10.1016/j.jece.2019.102916

31. Moreira AJ, Borges AC, Gouvea LFC, et al (2017) The process of atrazine degradation, its mechanism, and the formation of metabolites using UV and UV/MW photolysis. J Photochem Photobiol A Chem 347:160-167. https://doi.org/10.1016/j.jphotochem.2017.07.022

32. Moreira AJ, Campos LO, Maldi CP, et al (2020a) Photocatalytic degradation of Prozac® mediated by TiO2 nanoparticles obtained via three synthesis methods: sonochemical, microwave hydrothermal, and polymeric precursor. Environ Sci Pollut Res 27:27032-27047. https://doi.org/10.1007/s11356020-08798-X

33. Moreira AJ, Malafatti JOD, Giraldi TR, et al (2020b) Prozac® photodegradation mediated by Mndoped $\mathrm{TiO}<\mathrm{inf}>2</ \mathrm{inf}>$ nanoparticles: Evaluation of by-products and mechanisms proposal. J Environ Chem Eng 8:. https://doi.org/10.1016/j.jece.2020.104543

34. Moreira AJ, Pinheiro BS, Araújo AF, Freschi GPG (2016) Evaluation of atrazine degradation applied to different energy systems. Environ Sci Pollut Res 23:. https://doi.org/10.1007/s11356-016-6831-x

35. Moyet MA, Arthur RB, Lueders EE, et al (2018) The role of Copper (II) ions in Cu-BiOCl for use in the photocatalytic degradation of atrazine. J Environ Chem Eng 6:5595-5601. https://doi.org/10.1016/j.jece.2018.08.057

36. Muniz FTL, Miranda MAR, Morilla Dos Santos C, Sasaki JM (2016) The Scherrer equation and the dynamical theory of X-ray diffraction. Acta Crystallogr Sect A Found Adv 72:385-390. https://doi.org/10.1107/S205327331600365X 
37. Paris EC, Malafatti JOD, Sciena CR, et al (2020) Nb2O5 nanoparticles decorated with magnetic ferrites for wastewater photocatalytic remediation. Environ Sci Pollut Res. https://doi.org/10.1007/s11356-020-11262-5

38. Parmar A, Sharma S (2016) Derivative UV-vis absorption spectra as an invigorated spectrophotometric method for spectral resolution and quantitative analysis: Theoretical aspects and analytical applications: A review. TrAC - Trends Anal Chem 77:44-53. https://doi.org/10.1016/j.trac.2015.12.004

39. Rincón Joya M, Barba Ortega J, Malafatti JOD, Paris EC (2019) Evaluation of Photocatalytic Activity in Water Pollutants and Cytotoxic Response of a-Fe2O3 Nanoparticles. ACS Omega 4:17477-17486. https://doi.org/10.1021/acsomega.9b02251

40. Rodrigues ET, Alpendurada MF, Ramos F, Pardal MÂ (2018) Environmental and human health risk indicators for agricultural pesticides in estuaries. Ecotoxicol Environ Saf 150:224-231. https://doi.org/10.1016/j.ecoenv.2017.12.047

41. Ruckebusch C, Blanchet $L$ (2013) Multivariate curve resolution: A review of advanced and tailored applications and challenges. Anal Chim Acta 765:28-36. https://doi.org/10.1016/j.aca.2012.12.028

42. Samsudin EM, Abd Hamid SB, Juan JC, et al (2016) Synergetic effects in novel hydrogenated Fdoped TiO 2 photocatalysts. Appl Surf Sci 370:380-393. https://doi.org/10.1016/j.apsusc.2016.02.172

43. Samsudin EM, Abd Hamid SB, Juan JC, et al (2015) Controlled nitrogen insertion in titanium dioxide for optimal photocatalytic degradation of atrazine. RSC Adv 5:44041-44052. https://doi.org/10.1039/c5ra00890e

44. Silva CD, Corradini PG, Mascaro LH, et al (2019) Using a multiway chemometric tool in the evaluation of methanol electro-oxidation mechanism. J Electroanal Chem 855:1-7. https://doi.org/10.1016/j.jelechem.2019.113598

45. Singh S, Kumar V, Chauhan A, et al (2018) Toxicity, degradation and analysis of the herbicide atrazine. Environ Chem Lett 16:211-237. https://doi.org/10.1007/s10311-017-0665-8

46. Souza TS, Zanin HG, Peterlevitz A, et al (2016) MCR-ALS APPLIED TO THE QUANTITATIVE MONITORING OF THE ELECTRODEGRADATION PROCESS OF ATRAZINE USING UV SPECTRA: COMPARATIVE RESULTS WITH HPLC-DAD AS A REFERENCE METHOD. Quim Nova 39:137-145. https://doi.org/10.5935/0100-4042.20160006

47. Tripathi AK, Singh MK, Mathpal MC, et al (2013) Study of structural transformation in TiO2 nanoparticles and its optical properties. J Alloys Compd 549:114-120. https://doi.org/10.1016/j.jallcom.2012.09.012

48. Truc NTT, Duc DS, Van Thuan D, et al (2019) The advanced photocatalytic degradation of atrazine by direct Z-scheme Cu doped ZnO/g-C3N4. Appl Surf Sci 489:875-882. https://doi.org/10.1016/j.apsusc.2019.05.360

49. Wang WK, Chen JJ, Gao M, et al (2016) Photocatalytic degradation of atrazine by boron-doped TiO2 Catal B Environ 195:69-76. 
https://doi.org/10.1016/j.apcatb.2016.05.009

50. Weber G, Christmann N, Thiery AC, et al (2018) Pesticides in agricultural headwater streams in southwestern Germany and effects on macroinvertebrate populations. Sci Total Environ 619620:638-648. https://doi.org/10.1016/j.scitotenv.2017.11.155

51. Zhang G, Pan J (2011) Simultaneous spectrophotometric determination of atrazine and cyanazine by chemometric methods. Spectrochim Acta - Part A Mol Biomol Spectrosc 78:238-242.

https://doi.org/10.1016/j.saa.2010.09.028

52. Zhang J, Xin B, Shan C, et al (2021) Roles of oxygen-containing functional groups of O-doped gC3N4 in catalytic ozonation: Quantitative relationship and first-principles investigation. Appl. Catal. B Environ. 292

53. Zhao Y, Li C, Liu X, et al (2007) Synthesis and optical properties of TiO2 nanoparticles. Mater Lett 61:79-83. https://doi.org/10.1016/j.matlet.2006.04.010

\section{Figures}

(a)
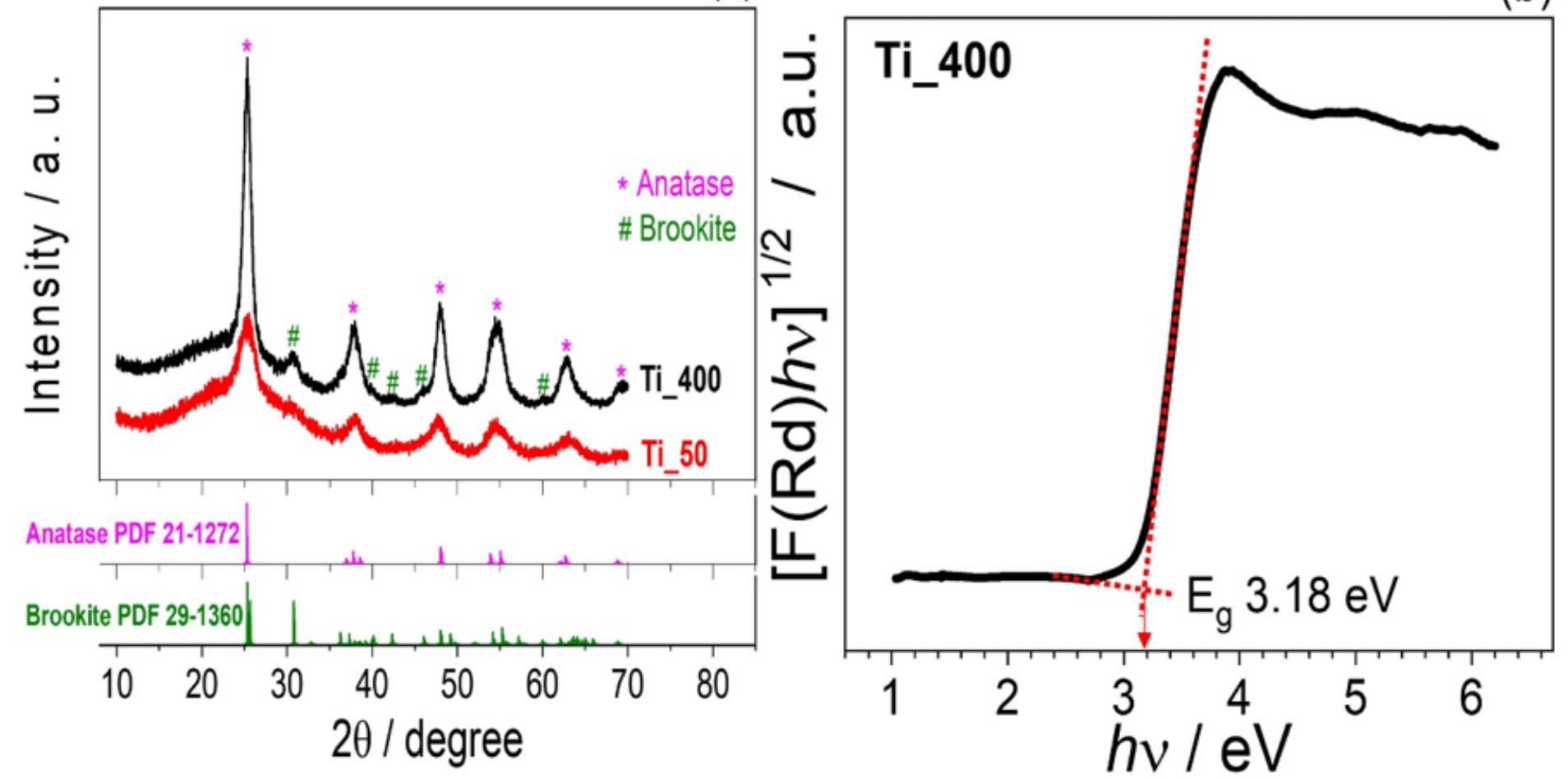

Figure 1

XRD diffraction pattern to Ti_50 and Ti_400 (a). Tauc plot of Ti_400 (b). 
(a)
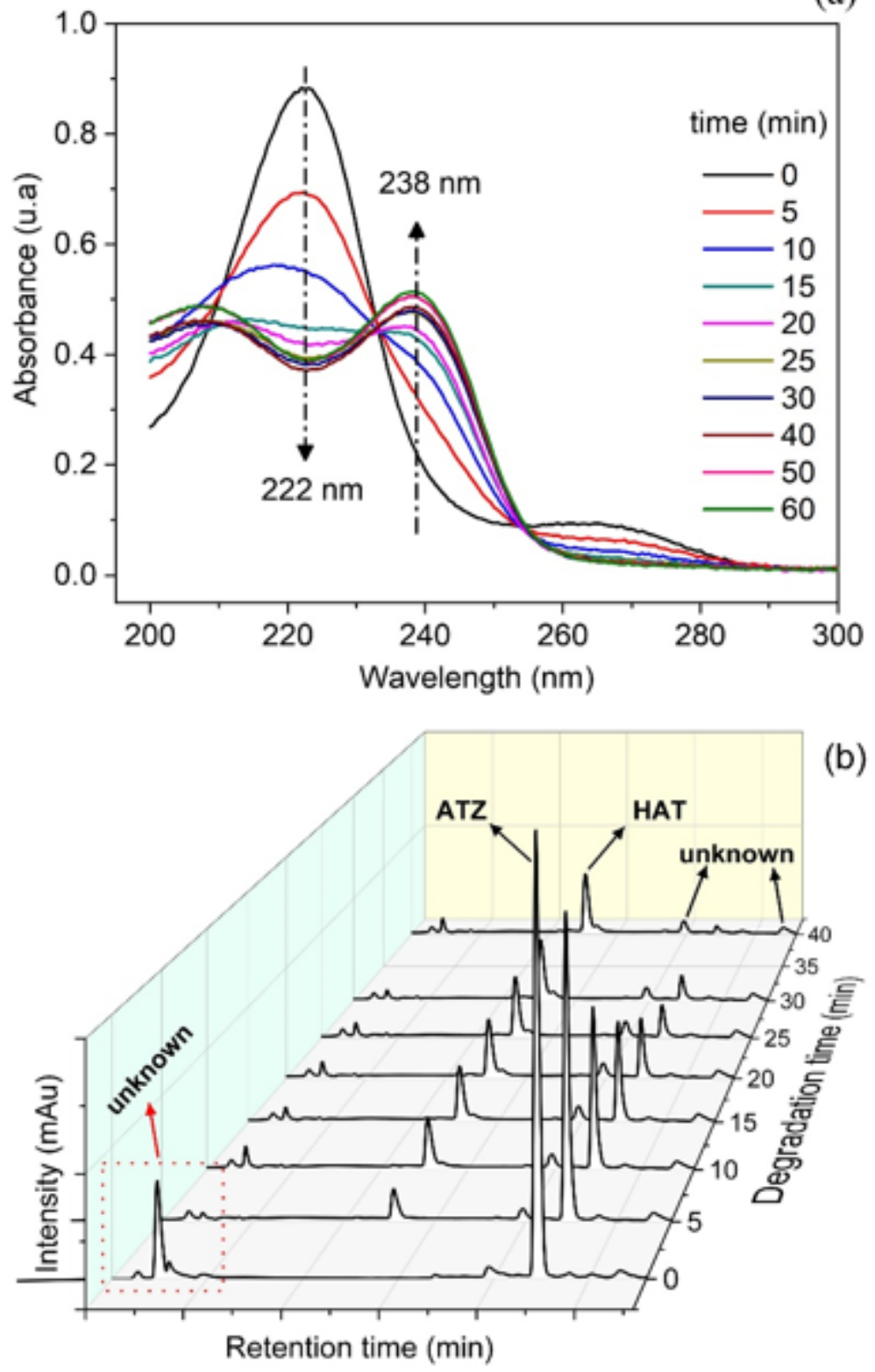

Figure 2

Molecular absorption spectra (a) and chromatographic profiles (b) of the UV photodegradation up to 60 min of a $5 \mathrm{mg} \mathrm{L-1}$ ATZ solution. 

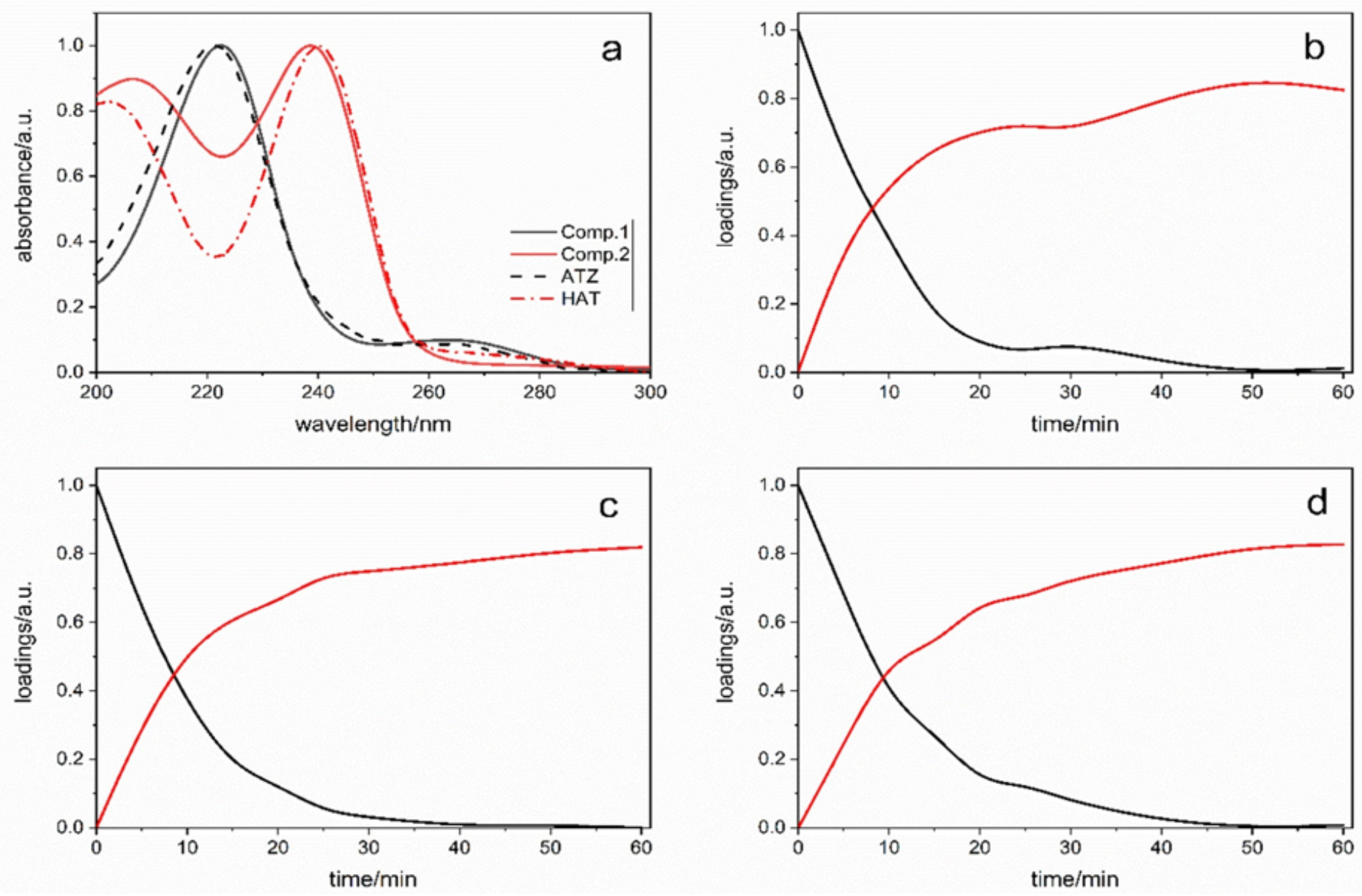

Figure 3

MCR-ALS resolved pure UV-Vis spectra (a) and kinetic profiles of the photolytic degradation of $3 \mathrm{mg} \mathrm{L}-1$ (b), $5 \mathrm{mg} \mathrm{L}-1$ (c), and $10 \mathrm{mg} \mathrm{L}-1$ (d) of ATZ. 
(a)

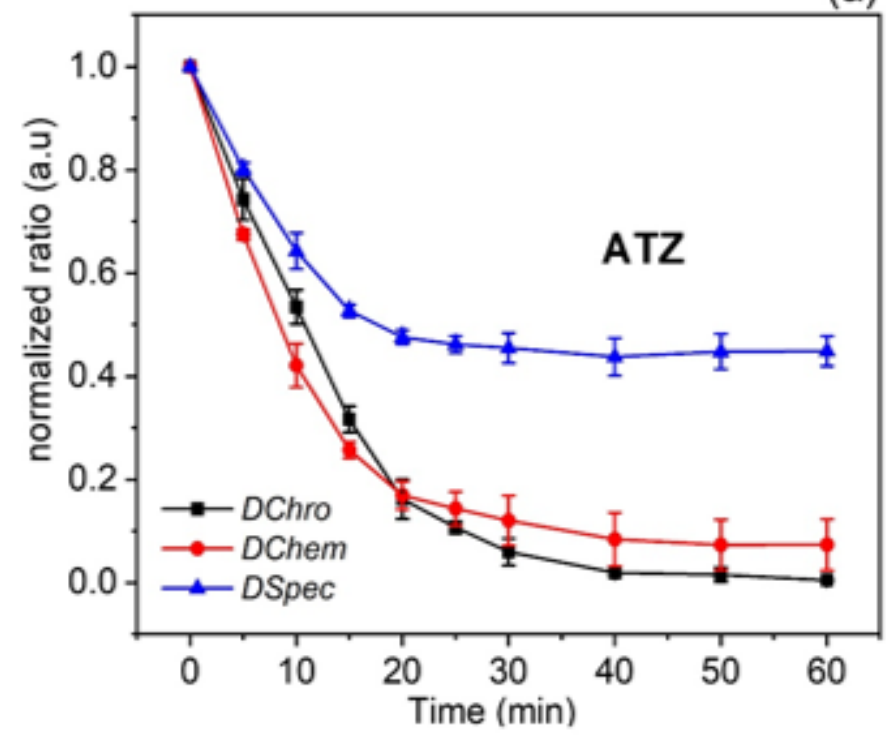

(b)

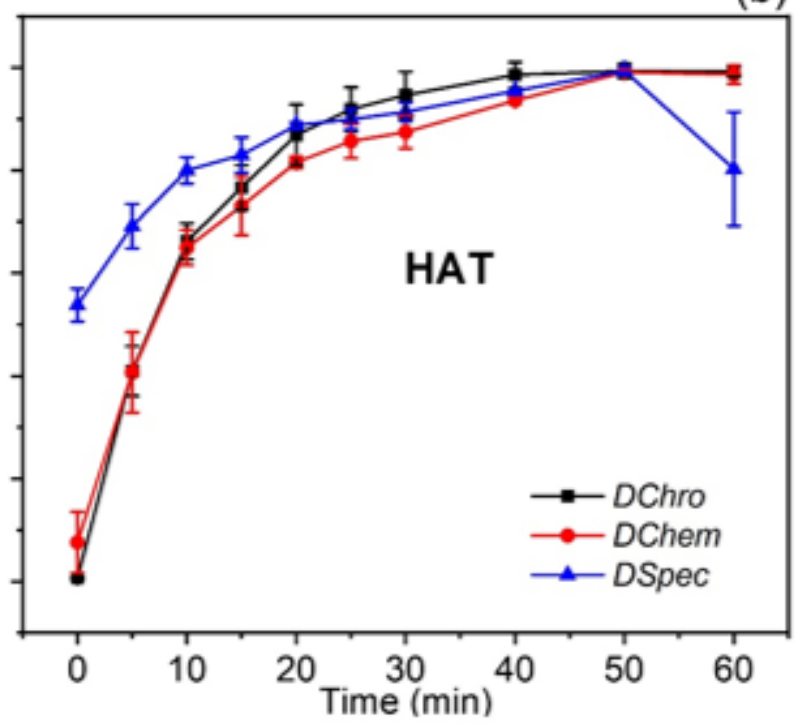

Figure 4

ATZ degradation (a) and HAT formation (b) calculated using normalized DSpec, DChro and DChem. 

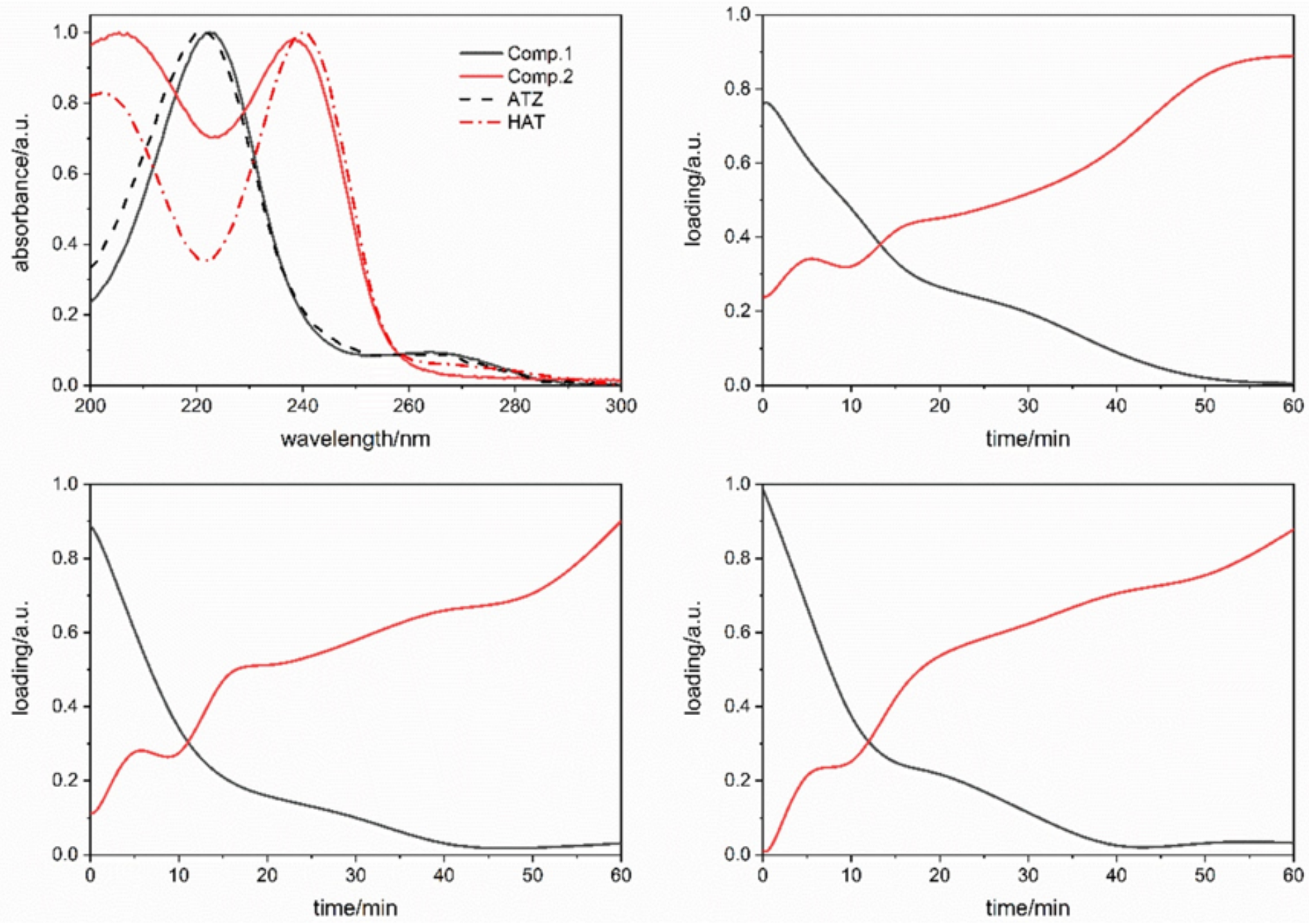

\section{Figure 5}

MCR-ALS resolved pure UV-Vis spectra (a) and kinetic profiles of the photocatalytic degradation of $3 \mathrm{mg}$ L-1 (b), 5 mg L-1 (c), and 10 mg L-1 (d) of ATZ with TiO2 (Ti_400) and UV radiation. 
(a)

(b)

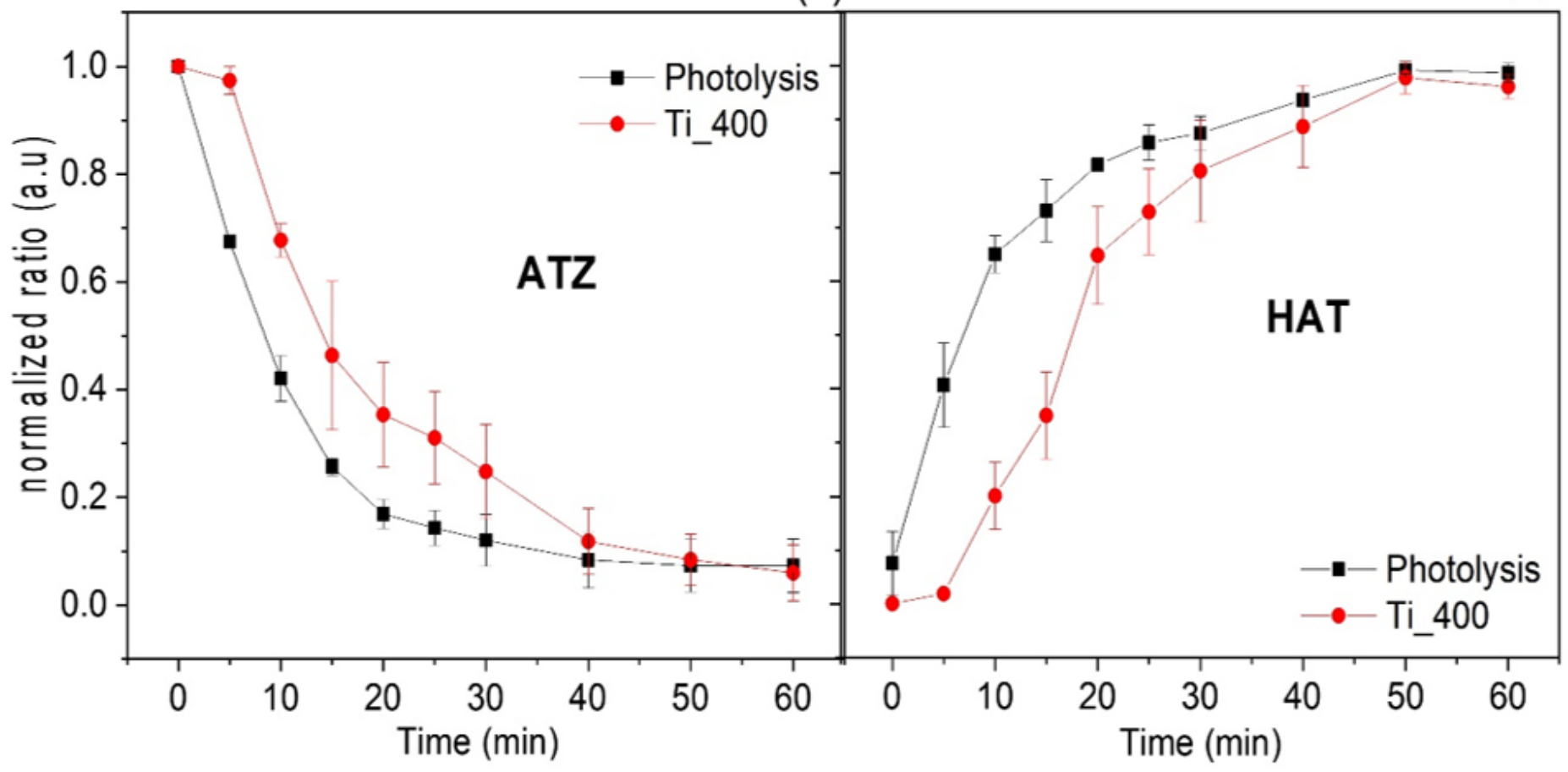

Figure 6

Comparison between photolytic and photocatalytic degradation of ATZ (a) and HAT formation (b) obtained with normalized DChem.

\section{Supplementary Files}

This is a list of supplementary files associated with this preprint. Click to download.

- GA.png

- Supplementarymaterial.docx 